\title{
Physical and Mechanical Properties of Fenugreek (Trigonella foenum-Graceum L.)
}

\author{
R. K. Rathod*, S. M. Mathur, B. B. Badgire and Mukesh Kumar Singh \\ Department of Farm machinery and power Engineering, CTAE, MPUAT, Udaipur, India \\ *Corresponding author
}

A B S T R A C T

\begin{tabular}{|l|}
\hline Ke y w o r d s \\
$\begin{array}{l}\text { Fenugreek seeds, } \\
\text { sphericity, } \\
\text { grain friction }\end{array}$ \\
\hline Article Info \\
\hline $\begin{array}{l}\text { Accepted: } \\
10 \text { April } 2020 \\
\text { Available Online: } \\
10 \text { May 2020 }\end{array}$ \\
\hline
\end{tabular}

Some physical and mechanical properties of fenugreek seeds and plant were evaluated. The average length, width, thickness and geometric mean diameter of fenugreek seed were $3.47 \mathrm{~mm}, 2.53 \mathrm{~mm}, 1.61 \mathrm{~mm}$ and $2.41 \mathrm{~mm}$, respectively. The observed mean value of fenugreek plant for length, width and stalk diameter was $593.12 \mathrm{~mm}, 118.16 \mathrm{~mm}$ and $2.48 \mathrm{~mm}$, respectively. The average values of sphericity, surface area, volume, thousand seed weight, bulk density, true density, porosity and angle of repose were $0.70 \mathrm{~mm}, 18.42 \mathrm{~mm}^{2}, 5.34 \mathrm{~mm}^{3}, 11.93 \mathrm{~g}$, $687.62 \mathrm{~kg} / \mathrm{m}^{3}, 1360.58 \mathrm{~kg} / \mathrm{m}^{3}, 49.39$ per cent and 37.21 degree. The coefficient of static friction was higher for plywood followed by acrylic, M.S. sheet and G. I. sheet. The coefficient of internal grain friction was 0.43 . The force required for rupturing the fenugreek seed in horizontal and vertical was recorded as 477 and $65.93 \mathrm{~N}$, respectively and force required for rupturing the fenugreek pod in horizontal orientation 53.16 and $8.11 \mathrm{~N}$, respectively. The average fenugreek stalk breaking force required was observed to be $24.72 \mathrm{~N}$.

\section{Introduction}

Fenugreek (Trigonella foenumgraecum L.) is an annual herb of the sub-family Papilionaceae of Leguminosae family. Fenugreek is a self-pollinated, small-seeded annual legume that is grown as a spice crop. Fenugreek (Trigonella foenum-graecum L. Family: Leguminosae) has two areas of origin, the Indian subcontinent and the Eastern Mediterranean Region. Fenugreek is considered to have originated in the Mediterranean region of the "Old World" (Vavilov, 1926) or in parts of Asia (De Candolle, 1964). The species name "foenumgraecum" means "Greek hay" indicating its use as a forage crop in the past, (Meena et al., 2012). The fenugreek seeds are the most important and useful part of fenugreek plant. These seeds are golden yellow in colour, small in size, hard and have four- faced stone like structure (Altuntas et al., 2005). 
To design equipment for aeration and storage there is a need to know various physical properties as a function of moisture content (Srivastava et al., 1990). The physical properties of fenugreek seeds are important in designing and optimization of harvesting, threshing, handling, storage and processing equipments and machineries. Also it is important for design and improvement of relevant machines.

The size and shape are important in designing of separating, harvesting, threshing, and grinding machines. Bulk density and porosity affect the structural loads. The angle of repose is important in designing of feeding hopper, storage and transporting structures. The coefficient of friction of the seed against the various surfaces is also necessary in designing of conveying, transporting and storing structures (Altuntas et al., 2005).

The accurate estimate of shape, size, terminal velocities, angle of repose, bulk density, thousand seed weight etc. were essential for development of the feeding hopper, threshing cylinder, concave and concave grate clearance, seed outlet, blower, sieves, seed outlet in threshing and crop handling machineries. These properties were influenced largely by the moisture content.

Fenugreek plant attains a height of about 30 to $60 \mathrm{~cm}$. It has compound pinnate, trifoliate leaves, axillary white to yellow flowers, and 3 to $15 \mathrm{~cm}$ long thin pointed hoop-like beaked pods. Each pod contains 10-20 oblong greenish-brown seeds with unique hooplike groves (Srinivasan, 2006). The fenugreek seeds are the most important and useful part of fenugreek plant. These seeds are golden yellow in colour, small in size, hard and have four- faced stone like structure (Altuntas et $a l ., 2005)$. The objective of this study was to investigate physical and mechanical properties of fenugreek seeds and plant.
The investigated physical properties of fenugreek seeds were viz. spatial dimension, sphericity, surface area, volume, thousand seed weight, bulk density, true density, porosity, angle of repose, the static coefficient of friction and angle of friction on various surfaces, coefficient of internal grain friction, force required for rupturing seed and pod, fenugreek stalk breaking force.

\section{Materials and Methods}

The fenugreek seed of variety RMt-305 was selected for this study, the selected seeds samples were cleaned manually. The initial moisture content of the samples was determined by oven drying at $105 \pm 1{ }^{\circ} \mathrm{C}$ for 24 (Suthar \& Das, 1996; Altuntas et al., 2005). The moisture content of fenugreek seed was calculated on dry basis using following relationship.

$$
\mathrm{Mdb}=\frac{\mathrm{ww}}{\mathrm{wd}} \times 100
$$

Where, $\mathrm{M}_{\mathrm{db}}$ is moisture content on dry basis (\%); $\mathrm{W}_{1}$ is initial weight of seeds, $\mathrm{g} ; \mathrm{W}_{\mathrm{w}}$ is weight of water $\left(\mathrm{w}_{1}-\mathrm{w}_{\mathrm{d}}\right), \mathrm{g} ; \mathrm{W}_{\mathrm{d}}$ is weight of dry matter, g.

\section{Spatial dimensions}

The physical properties of the fenugreek seeds were investigated for randomly selected 50 fenugreek seeds of variety $R M t-305$. The spatial dimensions viz. length, width and thickness of a fenugreek seed and plant were measured. For each seed, three linear dimensions namely length, width and thickness in $\mathrm{mm}$, were measured by using digital vernier caliper having least count of $\pm 0.01 \mathrm{~mm}$. The overall spatial dimensions of fenugreek plant such as plant length, width and maximum diameter of the branches were measured with steel rule and digital vernier caliper with $\pm 0.01 \mathrm{~mm}$ least count. 


\section{Geometric mean diameter and sphericity}

The geometric mean diameter $(\mathrm{Dg})$ and Sphericity of fenugreek seeds was calculated by using the following equations (Mohsenin, 1970).

$\mathrm{D}_{\mathrm{g}}=\sqrt[s]{(\mathrm{LWT})}$

Sphericity $=\frac{\sqrt[3]{ }((L W T))}{L}$

Where,

$\mathrm{L}$ is the length, $\mathrm{mm}$; $\mathrm{W}$ is width, $\mathrm{mm}$ and $\mathrm{T}$ is thickness, $\mathrm{mm}$

\section{Surface area and volume}

The surface area (Sa) was calculated using the values obtained for geometric mean diameter $(\mathrm{Dg})$. The surface area measurement of fenugreek seed was useful to know the flow ability of a seed in a fluid i.e. air. The surface area of fenugreek seed was calculated using the following formula (Mohsenin, 1970).

$$
\mathrm{Sa}=\left(\pi \times \mathrm{Dg}^{2}\right)
$$

And, the volume of seed was calculated by using the following formula (Jain and Bal, 1997)

$$
V=\frac{\Pi \times B^{2} \mathrm{xL}^{2}}{6 \mathrm{x}(2 \mathrm{~L}-\mathrm{B})}
$$

Where,

$$
\mathrm{B}=\sqrt{\mathrm{WT}}
$$

\section{Thousand seeds weight}

The randomly 1000 seeds of fenugreek were selected and weighed on electronic weighing balance with accuracy of \pm 0.001 gram.

\section{Bulk density}

The procedure as given by the Balasubramanium (1985) followed by Narvani and Panwar (1993), was used to measure the bulk density of the fenugreek seed. For the fenugreek seed, a measuring cylinder of known volume (recorded in cubic meter) was filled with the fenugreek seeds, then the weight of same material was measured and the bulk density was calculated. For calculation of the bulk density following relationship was used.

$$
B_{d}=\frac{w_{s}}{v_{c}}
$$

Where, $B_{d}$ is bulk density, $\left(\mathrm{kg} / \mathrm{m}^{3}\right)$; Ws is weight of seeds, $(\mathrm{Kg}) ; \mathrm{V}_{\mathrm{c}}$ is volume of the measuring cylinder, $\left(\mathrm{m}^{3}\right)$.

\section{True density}

The true density of the fenugreek seed was determined by toluene displacement method. A $500 \mathrm{ml}$ measuring cylinder was taken, which was filled with the $250 \mathrm{ml}$ of toluene. Pre-weighed fenugreek seed were dropped inside the measuring cylinder, the increased level of toluene was recorded. The difference of the toluene level in both the readings was noted as the displaced volume (true volume) of the toluene. The true density was calculated by taking the ratio of weight of fenugreek seed to the displaced volume of toluene. The same procedure was replicated for twenty times and the mean of twenty readings were considered as the true density of the fenugreek seed. The following relationship was used to calculate true density (Mohsenin, 1970).

True density, $\mathrm{Kg} / \mathrm{m}^{3}=\frac{\text { Weight of fenugreek seeds }(\mathrm{Kg})}{\text { True volume of fenugreek seeds, }\left(\mathrm{m}^{\mathrm{g}}\right)}$ 


\section{Porosity}

The porosity of fenugreek seed was determined from the obtained values of bulk density and true density of fenugreek seed using the following expression (Mohsenin, 1970).

Porosity (\%) $=1-\frac{\text { True density }- \text { Bulk Density }}{\text { True density }}$ X 100

\section{Angle of repose}

The angle of repose is the angle between the base and the slope of the cone formed on a free vertical fall of the fenugreek seed to a horizontal plane. The angle of repose indicates the cohesion among the seeds. Higher is the angle of repose, higher will be the cohesion. The fenugreek seed allowed escaping from funnel, leaving a free-standing cone on the circular platform.

The angle of repose was measured by measurement of the height and diameter formed by the heap on the surface. The test procedure was replicated for fifteen times, the mean of the fifteen replications represented the angle of repose of fenugreek seed. The angle of repose was obtained from the geometry of the cone given as.

$\theta=\tan ^{-1}\left(\frac{2 \mathrm{~h}}{\mathrm{D}}\right)$

Where, $\theta$ is angle of repose, in degree; $h$ is height of heap in meter; $\mathrm{D}$ is base diameter of the heap in meter.

\section{Terminal velocity}

The terminal velocity is the measurement of airflow rate at which the material will terminate from its resting position and remains suspended in air tunnel. The variable speed blower was used for control of airflow. The air velocity at which the fenugreek seed remain suspended in air was measured as the terminal velocity of the fenugreek seed.

\section{Frictional properties}

The coefficient of friction is one of the important properties used for development of the grain or seed handling machineries. Frictional properties viz. coefficient of static friction, coefficient of internal seed friction and angle of friction by inclined plane method was determined as per the guidelines suggested by Kachru et al., (1994).

Coefficient of static friction was determined against different surfaces i.e. M.S. sheet, plywood, G. I. sheet and acrylic.

The angle of internal seed friction was determined by inclined method; the fenugreek seeds were filled in test box and placed at top of the test surfaces. The testing plane was tilted until the test sample began leaving an inclined surface, the plane was clamped in this position and the angle $\theta$ was recorded. The angle of inclination with the horizontal was taken as angle of friction.

The angle of friction was determined by inclined plane method. The fenugreek seeds were filled in test box of and placed on the test surface at the top edge. The testing plane was tilted until the test sample began leaving an inclined surface, the plane was clamped in this position and the angle $\theta$ was recorded.

The angle of inclination with the horizontal was taken as angle of friction. The angle of friction was determined by using relationships given below,

$$
\mu=\tan \theta
$$

Where, $\mu$ is coefficient of friction; $\theta$ is value of the angle. 


\section{Seed and pod rupturing force}

Fenugreek seed and pod orientation were kept in horizontal and vertical and then seed and pod rupturing force was determined on texture analyzer. The fenugreek stalk breaking force was also determined on texture analyzer.

\section{Results and Discussion}

The spatial dimension was determined from the measurement of length, width and thickness of fenugreek seed and plant at the moisture content of 8.85 and 8.61 per cent, respectively. About 76 per cent of fenugreek seeds had a length ranged from 3.01-4.18 $\mathrm{mm}$, about 78 per cent of seeds had width ranged from $2.41-2.98 \mathrm{~mm}$ and about 84 per cent of a seeds had a thickness ranged from $1.41-2.10 \mathrm{~mm}$ (fig. 1). The obtained values for length, width, thickness and geometric mean diameter of fenugreek seed ranged from 2.76 to $4.18 \mathrm{~mm}, 1.61$ to $2.98 \mathrm{~mm}, 1.28$ to $2.10 \mathrm{~mm}$ and 1.90 to $2.94 \mathrm{~mm}$, respectively. The mean value for length, width, thickness and geometric mean diameter of fenugreek seed was found to be $3.47 \mathrm{~mm}, 2.53 \mathrm{~mm}$, $1.61 \mathrm{~mm}$ and $2.41 \mathrm{~mm}$, respectively. The observed mean values of fenugreek plant for length, width and stalk diameter were 593.12 $\mathrm{mm}, 118.16 \mathrm{~mm}$ and $2.48 \mathrm{~mm}$, respectively.

The sphericity ranged between 0.61 to 0.84 $\mathrm{mm}$ and the mean value of sphericity was observed to be $0.70 \mathrm{~mm}$. The surface area and volume ranged between 11.35 to $27.15 \mathrm{~mm}^{2}$ and 2.38 to $9.45 \mathrm{~mm}^{3}$, respectively and mean values of surface area and volume was observed to be $18.42 \mathrm{~mm}^{2}$ and $5.34 \mathrm{~mm}^{3}$.

The thousand seed weight ranged between the 11.64 to 12.16 grams for the fenugreek seed and the mean thousand seeds weight was obtained to be 11.93 grams.
The bulk density of fenugreek seeds was found to be 682.56 to $691.62 \mathrm{~kg} / \mathrm{m}^{3}$ and the mean value of bulk density as $687.62 \mathrm{~kg} / \mathrm{m}^{3}$. The true density of fenugreek seed was observed between $1282.05-1470.59 \mathrm{~kg} / \mathrm{m}^{3}$ and the mean true density as $1360.58 \mathrm{~kg} / \mathrm{m}^{3}$.

The porosity of the fenugreek seed was observed to be 46.38 to 53.24 per cent and the mean value of porosity was 49.39 per cent. The range of angle of repose obtained for fenugreek seed was found to be 34.43 to 39.36 degree and the mean value of angle repose was 37.21 degree.

The measured range for terminal velocity was found to be 8.97 to $9.27 \mathrm{~m} / \mathrm{s}$ and the mean value as $9.14 \mathrm{~m} / \mathrm{s}$. The obtained results of coefficient of static friction for different base material viz. M.S. sheet and plywood, G. I. sheet and acrylic were $0.49-0.52,0.52-0.54$, $0.48-0.51$ and $0.51-0.54$, respectively. The mean coefficient of static friction was observed to be $0.51 \pm 0.01,0.53 \pm 0.01,0.50$ \pm 0.01 and $0.52 \pm 0.01$ for M.S. sheet, plywood, G. I. sheet and acrylic, respectively. From the observed values, the coefficient of static friction was higher for plywood followed by acrylic, M.S. sheet and G. I. sheet. For the M.S. sheet and G. I. sheet the value of coefficient of static friction observed to be very near to one another.

The observed range for coefficient of internal grain friction was $0.39-0.45$ and the mean coefficient of internal grain friction was observed to be 0.43 .

The obtained results of angle of friction for various base material viz. plywood, M.S. sheet, acrylic and G. I. sheet was observed to be $26^{\circ}-27^{\circ}, 26^{\circ}-28^{\circ}, 27^{\circ}-28^{\circ}$ and $26^{\circ}-27^{\circ}$, respectively. The mean value of angle of friction was $27.9^{\circ}, 27^{\circ}, 27.7^{\circ}$ and $26.75^{\circ}$ for plywood, M.S. sheet, acrylic and G. I. sheet, respectively. 
The force required for rupturing the fenugreek seed in horizontal orientation was $391.45 \mathrm{~N}$ to $507.23 \mathrm{~N}$ and that in the vertical orientation was observed to be 65.23 to $67.18 \mathrm{~N}$. The mean force in horizontal and vertical orientation was recorded as $477.00 \mathrm{~N}$ and $65.93 \mathrm{~N}$, respectively. It shows that less force is required in rupturing the fenugreek seed in vertical rather in horizontal position.
The force required for rupturing the fenugreek pod in horizontal orientation was 51.93 to $56.97 \mathrm{~N}$, and in the vertical orientation it was observed to be $7.86 \mathrm{~N}$ to $8.31 \mathrm{~N}$.

The mean force in horizontal and vertical was recorded as 53.16 and $8.11 \mathrm{~N}$, respectively. The average fenugreek stalk breaking force required was observed to be $24.72 \mathrm{~N}$.

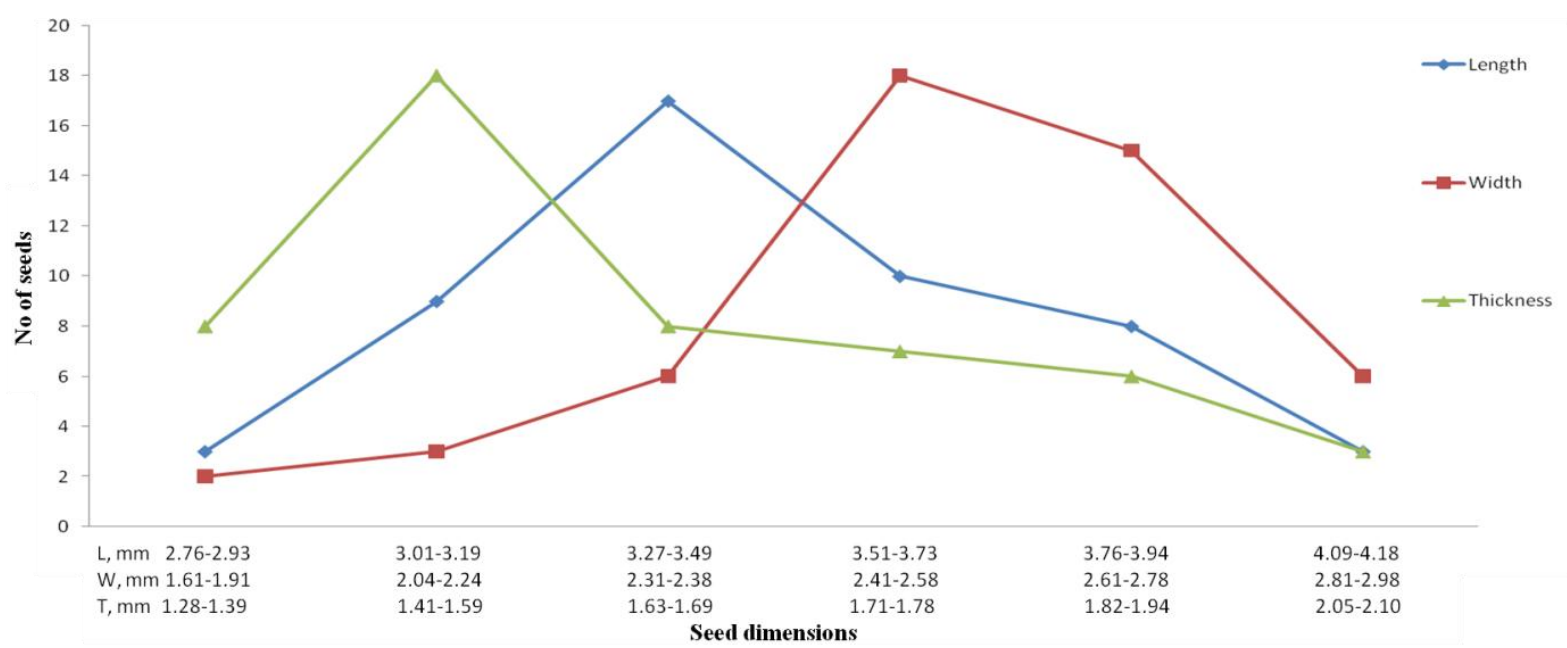

Figure.1 Frequency distribution curves of fenugreek seed length, width and thickness of the seed at $8.85 \%$ moisture content $(\mathrm{db})$

The average length, width, thickness and geometric mean diameter of fenugreek seed ranged from $3.47 \mathrm{~mm}, 2.53 \mathrm{~mm}, 1.61 \mathrm{~mm}$ and $2.41 \mathrm{~mm}$, respectively.

The observed mean value of fenugreek plant for length, width and stalk diameter was $593.12 \mathrm{~mm}, 118.16 \mathrm{~mm}$ and $2.48 \mathrm{~mm}$, respectively.

The average values of sphericity, surface area, volume, thousand seed weight, bulk density, true density, porosity and angle of repose was $0.70 \mathrm{~mm}, 18.42 \mathrm{~mm}^{2}, 5.34 \mathrm{~mm}^{3}, 11.93 \mathrm{~g}$, $687.62 \mathrm{~kg} / \mathrm{m}^{3}, 1360.58 \mathrm{~kg} / \mathrm{m}^{3}, 49.39$ per cent and 37.21 degree.

The coefficient of static friction was higher for plywood followed by acrylic, M.S. sheet and G. I. sheet.
The force required for rupturing the fenugreek seed and pod was less in vertical orientation than in horizontal orientation, also there is large variation in force that required in rupturing fenugreek seed in horizontal and in vertical position.

\section{References}

Altuntas, E., Ozgoz, E., Taser, O.F. 2005. Some physical properties of fenugreek (Trigonella foenum-graceum L.) seeds. Journal of food engineering. 71(2005): 37-43.

Balasubramanium, M., 1985. Studies on performance parameters of arecanut dehusking. Ph.D. Thesis, Division of Agricultural Engineering, IARI, New Delhi.

De Candolle, A. 1964. Origin of Cultivated 
Plants. Hafner publishing comp, New York. Vol.7.

Jain, R. K. and Bal, S. 1997. Properties of pearl millet. J.Agricultural Eng. Res. 66: 85-91.

Kachru, R. P., Gupta, R. K. and Alam, A. 1994. Physico-chemical constituents and engineering properties of food crops. Scientific Publishers, Jodhpur. India. Pp. 40- 90.

Meena, R. P., Kumar, P. R., Meena, R. P. 2012. Cultivation of fenugreek for spice and quality seed. Spice India. 25(4):715.

Mohsenin, N. N. 1970. Physical properties of plant and animal materials. Second revised and updated edition, Gorden and Breach Sci. Publishers, New York. Pp. 79-127.

Narvani, N.B. and Panwar, J.S. 1993. Studies on physical and engineering
Properties related to threshing of saffflower crop. Karnataka Journal of Agricultural Sciences.6(1):37-40.

Srinivasan, K. 2006. Fenugreek (Trigonella foenum-graecum): A Review of Health Beneficial Physiological Effects. Food Reviews International. 22, 203- 224.

Srivastava, A. K., Mahoney, W. T., and West, N. L. 1990. The effect of crop properties on combine performance. Transactions of the ASAE. 33(1): 6372.

Suthar, S. H., and Das, S. K. 1996. Some physical properties of karingda (Citrus lanatus (thumb) mansf) seeds. Journal of Agricultural Engineering Research. 65(1): 15-22.

Vavilov, N. I. 1926. Centers of origin of cultivated plants. Bulletin of applied botany, genetics and plant breeding (In Russian). 16 (2):3-248.

\section{How to cite this article:}

Rathod. R. K., S. M. Mathur, B. B. Badgire and Mukesh Kumar Singh. 2020. Physical and Mechanical Properties of Fenugreek (Trigonella foenum-Graceum L.). Int.J.Curr.Microbiol.App.Sci. 9(05): 1250-1256. doi: https://doi.org/10.20546/ijcmas.2020.905.139 